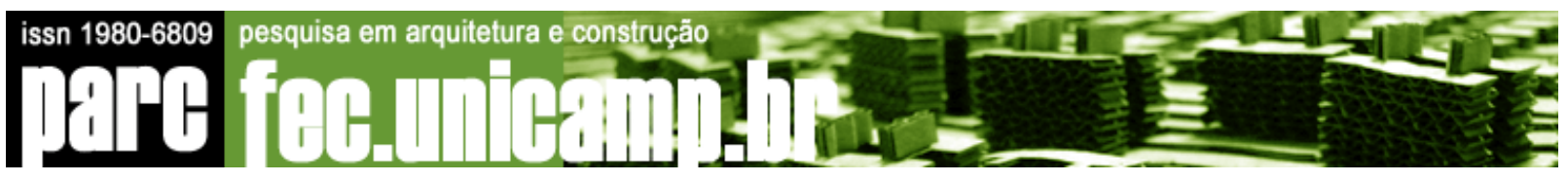

\title{
A Integração de conhecimento qualitativo no processo de projeto
}

The integration of qualitative knowledge into the design process

\section{RAQUEL R.M. PAULA BARROS}

Arquiteta pela Universidade de Brasília, Mestre pela University of Minnesota, Doutoranda pelo programa de Pós-Graduação da FEC-UNICAMP.

rpaulabarros@gmail.com

\section{Resumo}

O trabalho apresenta estratégia que propõe a integração de conhecimento qualitativo no processo de projeto a partir da valorização da relação entre conceitos humanizadores e a qualidade espacial do projeto da habitação coletiva. Os conceitos tiveram como ponto de partida seleção de patterns dentre os diversos originalmente identificados por Christopher Alexander e equipe em 1977. Desenvolveu-se estratégia metodológica que relaciona os conceitos humanizadores a propriedades que lhes são inerentes, representando qualidades do ambiente construído que podem resgatar um senso de urbanidade e de habitabilidade. Espera-se que a estratégia possa constituir base flexível para a emergência de idéias e contribua para a reflexão e prática do processo projetivo visando à melhoria da qualidade da habitação coletiva com relação ao melhor atendimento de necessidades sociais e psicológicas de futuros usuários.

Palavras-chave: processo de projeto, conceitos humanizadores, patterns, Christopher Alexander.

\section{Abstract}

This paper presents a strategy that proposes the integration of qualitative knowledge into the design process from valuing the relation between humanizing concepts and the spatial quality of multifamily housing design. The concepts originated from a selection of patterns related to housing among the identified by Christopher Alexander and colleagues in 1977. A design strategy was developed as to relate the humanizing concepts to inherent properties, representing qualities of the built environment which can recover a sense of urbanity and of a sense of dwelling. It is hoped that the strategy can work as a flexible basis for the emergence of ideas and contribute to the reflection on design methodologies and practice regarding the quality of multifamily housing concerning the fulfillment of social and psychological needs of future users.

Keywords: design process, humanizing concepts, patterns, Christopher Alexander. 


\section{A Integração de conhecimento qualitativo no processo de projeto}

\section{Introdução}

$\mathrm{O}$ ato de projetar em arquitetura envolve o ajuste responsável entre expectativas e problemas de ordem conflitante através da manipulação criativa de componentes de ordem programática e espacial, por sua vez indissociáveis das esferas sociocultural, ambiental, tecnológica, legal e econômica, dentre outras. Muitos projetistas se baseiam em repertório enriquecido com a experiência ao longo dos anos e em tentativas e erros para solucionar as questões e conflitos de projeto. Mas o processo projetual que busca soluções de qualidade necessita, além de conhecimento sólido no campo de atuação, de base crítica interna que auxilie no direcionamento do projeto em formação sem, no entanto, mecanizá-lo a ponto de impossibilitar a emergência de novas idéias. A busca criativa pela solução de problemas neste processo requer os pensamentos divergente e convergente em equilíbrio, conforme observado por Lawson (1997). A criatividade projetual pode ser cultivada e uma variedade de ferramentas é bem-vinda como suporte a um processo em que regras por si só não conseguem resolver a totalidade dos problemas. Dentro deste contexto, visualiza-se a pertinência de contribuição para a fase da concepção projetual a fim de integrar conhecimento qualitativo e sua sistematização criativa na solução de problemas.

Acredita-se que o processo projetivo pode se beneficiar da inclusão de conhecimento sistematizado sem prejuízo à criatividade. Para Kowaltowski et al. (2006) a complexidade do projeto e a exigência da qualidade ambiental demandam um aprimoramento dos procedimentos adotados e a aplicação de metodologias mais sistemáticas de pesquisa e projeto. Em vista dos desafios crescentes e interesses contraditórios com os quais se deparam os projetistas e a fim de atender às necessidades dos usuários através da criação projetual abrigando a relação ambiente-comportamento, torna-se necessário incorporar conscientemente os fatores comportamentais no processo criativo.

Alexander et al. (1977) constituiu-se a peça teórica motivadora para a presente pesquisa. A partir da observação de variados eventos reincidentes entrelaçados à geometria espacial no ambiente construído e denominados patterns, Alexander et al. (1977) propõem linguagem que procura refletir um modo intemporal de construir, por sua vez investigado em Alexander (1979). Este modo intemporal seria capaz de liberar ordem fundamental inerente aos seres humanos, qualidade central e critério de vida numa cidade ou edificação. A linguagem proposta visa alcançar uma qualidade que, apesar de não poder ser nomeada, 


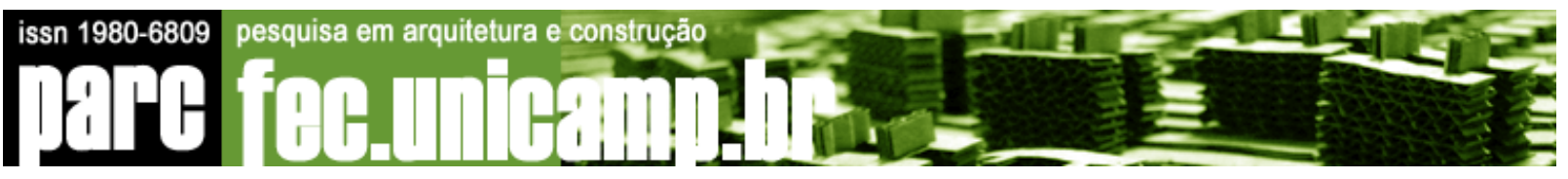

constitui o "caráter essencial e intemporal necessário à boa arquitetura" (1979, p.xv). Os autores Alexander et al. (1977) consideram que as linguagens usuais de projeto, ao contrário da linguagem proposta, são fragmentadas e não fundamentadas em considerações naturais e humanas, ou seja, não permitem a liberação daquela qualidade no ambiente construído que faz com que as pessoas se sintam vivas e humanas. Como um centro arquétipo para outras possíveis linguagens, a seqüência apresentada seria um mapa básico a partir do qual se pode configurar uma linguagem própria para cada projeto, escolhendo os patterns que lhe são mais úteis.

A pesquisa maior da qual este trabalho faz parte (BARROS, 2008) teve também como objeto de investigação o universo projetual da habitação coletiva. A amostra totaliza 35 projetos no Estado de São Paulo premiados e publicados nos periódicos nacionais entre os anos de 1980 e 2005, construídos ou não, incluindo qualquer faixa de renda de usuários, uma variedade de tipologias edilícias e escalas de intervenção. Acredita-se que o universo investigado requer atenção redobrada a aspectos não mensuráveis do conforto humano, tendo de atender a requisitos de variada ordem por vezes em conflito com necessidades sociais e psicológicas de uma diversidade de usuários, entre elas: vivacidade urbana, diferentes graus de privacidade e envolvimento comunitário, legibilidade, identidade, senso de proteção, variedade e expressividade sensorial. Considera-se que os índices e coeficientes típicos da legislação urbanística e arquitetônica são insuficientes para garantir a qualidade de projeto urbano e arquitetônico almejada: abrigar plenamente a relação ambiente-comportamento no projeto da habitação coletiva, o que inclui o resgate de um senso de lugar e de habitar desde a escala da implantação à escala da Unidade Habitacional (UH). Para tanto, partiu-se da obra de Alexander et al. (1977) como rico conhecimento estruturado sob a ótica da observação do comportamento humano no ambiente construído, cujo potencial de contribuição para o processo de projeto de intenção humanizadora parece, ainda hoje, subutilizado no Brasil, especialmente no âmbito da habitação coletiva. Apesar do reconhecimento por parte de pesquisadores e projetistas de variados equívocos na lógica de produção de projetos de habitação coletiva no Estado de São Paulo, a inserção urbana de tais conjuntos em variadas escalas de intervenção e para qualquer faixa de renda continua a impor desafios ao melhor atendimento das necessidades humanas aqui enfocadas. A valorização da relação entre conceitos humanizadores, construídos a partir de uma seleção de patterns originalmente identificados por Alexander et al. (1977), e a qualidade espacial de 


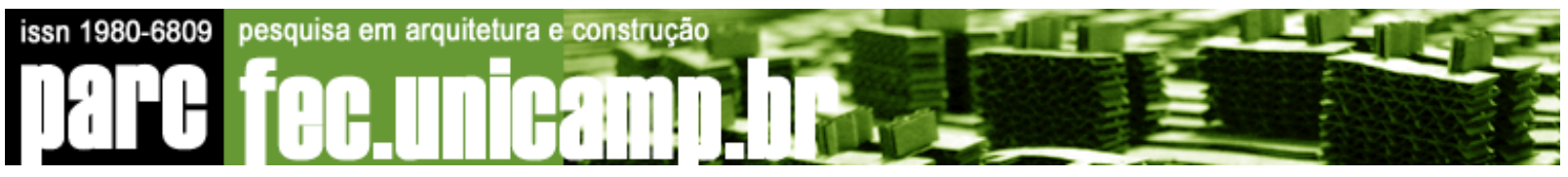

projetos de habitação coletiva, sugeriu o desenvolvimento de estratégia de apoio ao processo projetivo objeto do presente trabalho.

\section{Patterns, parâmetros projetuais e fatores de projeto}

Os patterns em Alexander et al. (1977) são apresentados pelos autores como proposições do tipo se - então, cada um descrevendo um problema recorrente no ambiente construído (se) e (então) as condições para uma solução são apresentadas e seguidas de croqui esquemático. Para os autores o uso dos patterns não necessariamente acarreta resultados formais semelhantes e a relação entre os patterns não é linear, visto que ocorre uma riqueza de conexões entre diferentes níveis. É premissa daquela proposta que o projetista seja alimentado por circunstâncias locais específicas. Muito embora estes esclarecimentos, os patterns têm por vezes sido considerados como de natureza determinista. Em detrimento desta interpretação, os patterns foram aqui traduzidos e interpretados como parâmetros projetuais. Acredita-se no caráter propositivo dos patterns e que a nomenclatura parâmetro enfatiza esta interpretação. Além de Alexander et al. (1977) e outras publicações do mesmo autor, co-autores e desdobramentos teóricos, buscou-se em Barros (2008) embasamento teórico com o intuito de esclarecer as implicações daquela obra para o processo projetual bem como de dar suporte à estratégia de apoio, tais como Jones (1969), Rowe (1995), Lawson (1997), Jutla (1983) e Norberg-Schulz (1965; 1976). Subsídios teóricos mais diretamente relacionados ao conteúdo dos parâmetros projetuais foram também revisados a fim de relacioná-los a outras teorias e pesquisas.

Os parâmetros projetuais procuram responder a problemas recorrentes no ambiente construído quanto ao melhor atendimento de necessidades sociais e psicológicas dos usuários. Foram selecionados aqueles relacionados ao tema habitacional, dentre os 253 descritos e pertencentes a quaisquer das três seções em Alexander et al. (1977), correspondentes às escalas de intervenção da cidade, da edificação e da construção. Buscou-se extrair daquela seleção preliminar de parâmetros o seu significado como fatores para o projeto da habitação coletiva relacionados ao atendimento daquelas necessidades humanas.

Sob a ótica metodológica a pesquisa em Barros (2008) é de caráter exploratório visto que investiga o potencial de parâmetros para a análise projetual e para a proposta de estratégia. Os objetos de estudo -- a seleção de parâmetros em Alexander et al (1977) e os projetos levantados -- consistem de fontes documentais. A percepção arquitetônica dos 


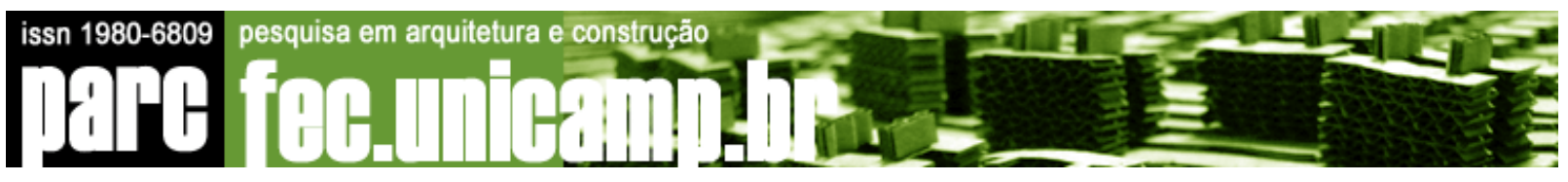

projetos buscou apreender os elementos que determinam a experiência dos ambientes e sua relação com os parâmetros selecionados, e se deu sobre os infográficos implantação, plantas do pavimento-tipo e da UH, e cortes. A heterogeneidade da amostra de projetos se justifica pela desejada abrangência de situações a fim de exemplificar os variados parâmetros investigados. A presença destes nos projetos se deu ora de maneira branda ora de maneira literal e, além disso, durante a análise dos mesmos, alguns dos parâmetros mostraram-se mais relevantes do que outros como fatores de projeto para o atendimento daquelas necessidades. Estas constatações instigaram uma interpretação mais aberta dos parâmetros e, posteriormente, à construção de conceitos a partir deles.

\section{A construção de conceitos humanizadores}

A tradução e interpretação dos patterns como parâmetros projetuais possibilitou reconhecê-los nos projetos de maneiras diversas. A variabilidade de um mesmo parâmetro em diferentes projetos demonstrou sua riqueza e adaptabilidade, desejável para uso em proposta de estratégia projetual propositiva, cujos parâmetros não determinam resultados formais necessariamente semelhantes. A relevância de alguns parâmetros projetuais levou à identificação de parâmetros-chave que desencadeiam a presença de outros parâmetros, descritos e ilustrados na TAB. 1 a seguir: 


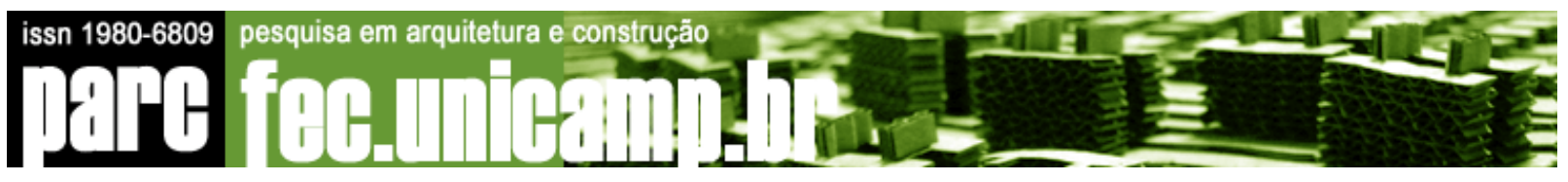

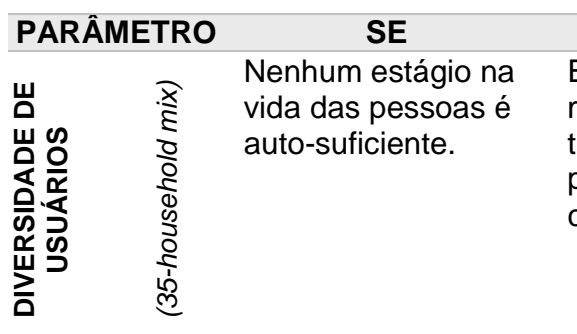

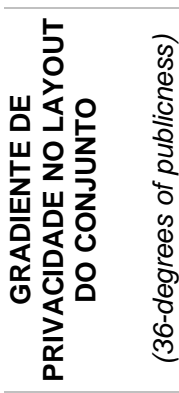

Posicionamento de unidades num agrupamento reflete diferenças entre pessoas.

\section{ENTÃO}

Encorajar variedade de usuários num mesmo bairro habitacional, de modo a ter, lado a lado, habitações de pessoas sozinhas, casais, famílias com crianças, habitações agrupadas.

Distinguir três tipos de unidades: fisicamente reservadas (mais silenciosas); mais públicas, (ruas movimentadas); meio-termo entre as outras duas.
CROQUIS
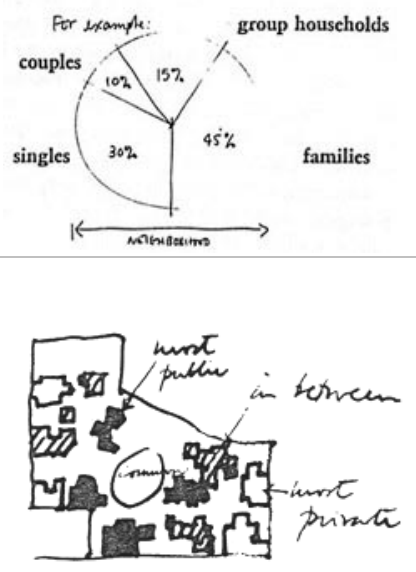

Considerar edifício e terreno como ecossistema único: não invadir áreas mais confortáveis e sadias, e sim construir nas áreas menos agradáveis, de pior condição topográfica, de orientação e vegetação, para melhorá-las.

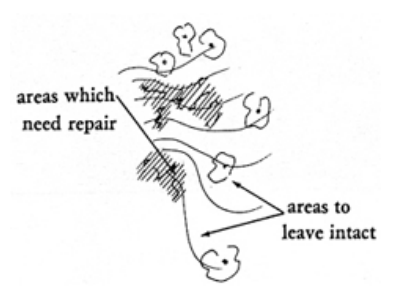

Criar espaços externos positivos ao redor dos edifícios, dotando-Ihes de algum grau de fechamento por meio de: alas de edifícios, árvores, cercas, arcadas, pergolados.
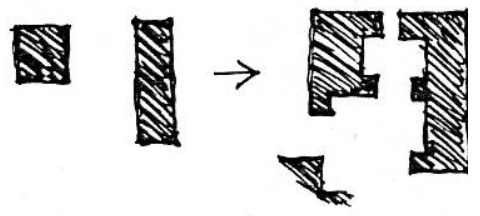

TABELA 1: Patterns considerados parâmetros-chave na construção dos conceitos. Número e nome originais dos patterns em itálico. Fonte: ALEXANDER et al., 1977, p.190, 195, 511 e 521.

A identificação dos parâmetros projetuais e dos parâmetros-chave nos projetos da amostra possibilitou a obtenção de categorização de parâmetros que contempla os temas da Sustentabilidade ambiental e social, Vivacidade urbana, Identidade e Privacidade. Uma categorização em arranjo concêntrico salienta os parâmetros-chave (posicionados no centro) e seus respectivos desencadeamentos. Na FIG.1, a seguir, os parâmetros se encontram representados pelos respectivos números originais em Alexander et al. (1977), sendo que o número de um novo parâmetro identificado se encontra sempre precedido pela letra "N". O arranjo concêntrico representado na FIG.1 auxiliou na visualização das associações identificadas entre os parâmetros projetuais de diferentes categorias. 

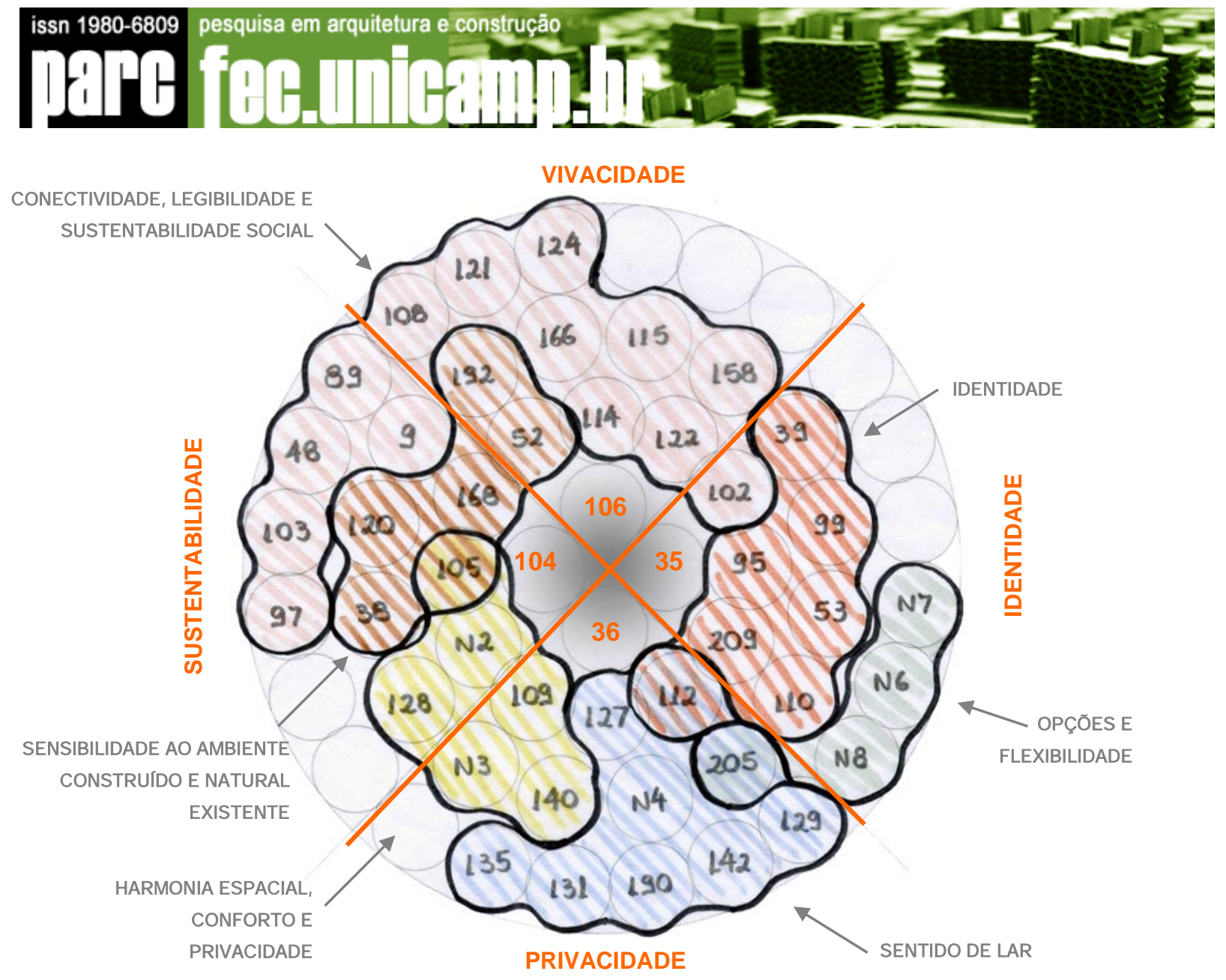

FIGURA 1: Categorização de parâmetros projetuais em arranjo concêntrico e associações.

A análise dos projetos indicou que são associações entre parâmetros e não parâmetros projetuais isolados que apresentam maior relevância para aquela análise. Essas associações fomentaram assim a construção de conceitos humanizadores de caráter propositivo (indicados na FIG.1), apresentados primeiramente sob os enfoques abrangentes do senso de urbanidade e de habitabilidade e, em seguida, nas subcategorias detalhadas no Desenvolvimento da estratégia metodológica.

\section{O SENSO DE URBANIDADE}

Esta categoria de conceitos se refere mais diretamente à escala da implantação das edificações. O alcance do senso de urbanidade no projeto de habitação coletiva vai além do simples provimento de espaços coletivos e áreas verdes requeridos pela legislação: por meio da sensibilidade ao ambiente construído e natural existente, recursos espaciais específicos aliados a parâmetros para a sustentabilidade social podem contribuir para a percepção de um sentido de lugar, para a vivacidade urbana e para a diminuição da segregação social e da dificuldade de locomoção. A integração dos espaços externos às edificações se traduz em 


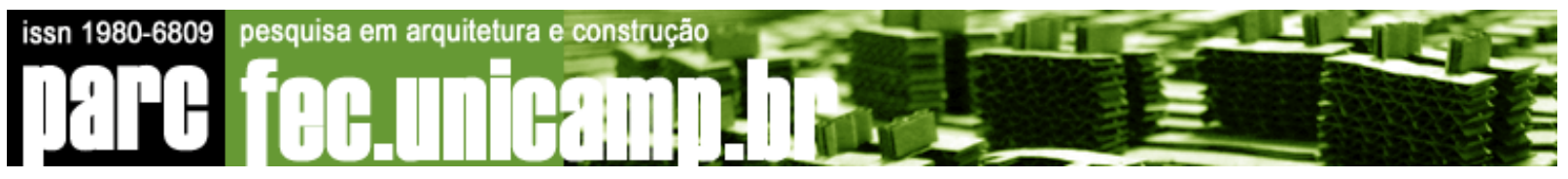

sistemas de lugares que proporcionam conectividade espacial, legibilidade e identidade, expressando diversidade de usuários, de faixas de renda e uso misto quando cabível. São considerados o impacto de diferentes organizações espaciais no ambiente construído e natural existente, do grau de conformação, da acessibilidade e da hierarquia entre espaços externos para o provimento do senso de proteção, permeabilidade e legibilidade dos percursos.

\section{O SENSO DE HABITABILIDADE}

Esta categoria abrange os conceitos referentes à escala da edificação e das UHs em si. O alcance do senso de habitabilidade no projeto de habitação coletiva vai além do atendimento das necessidades mínimas requeridas pela legislação no que se refere a iluminação e ventilação naturais, área $\left(\mathrm{m}^{2}\right)$ e dimensões para as diversas atividades domésticas: proporciona um sentido de lar que preenche as necessidades de refúgio, lugar, ordem, variedade, convivência e isolamento.

\section{Desenvolvimento da estratégia metodológica}

A análise dos projetos sob o enfoque dos parâmetros projetuais em Barros (2008) indicou a necessidade de se evidenciar, na proposta de estratégia, a complexidade da linguagem de parâmetros original em Alexander et al. (1977). Considera-se que, embora real, esta complexidade não se encontra suficientemente evidenciada naquela obra, que os apresenta mais como coleção do que como sistema. A construção de conceitos que combinam parâmetros entre níveis diferentes na estratégia proposta visam salientar a importância das conexões hierárquicas entre parâmetros de um mesmo nível bem como de diferentes níveis. Acredita-se que o modelo de representação de valores usado no processo projetual é fator importante para sua dinâmica, visão também reforçada por Laseau (1989). Assim sendo, a estratégia de apoio almeja clareza de representação dos valores identificados e incorporados nos conceitos humanizadores, a fim de estimular seu uso efetivo e criativo no processo de projeto.

Confirmando o ponto de vista, Salingaros (2000) adverte para o perigo em se considerar a obra Alexander et al. (1977) apenas um catálogo de parâmetros: uma coleção frouxa de parâmetros não é um sistema já que não apresenta conexões. Em sistemas complexos há estrutura hierárquica: processos e conexões ocorrem no mesmo nível bem como em níveis diferentes e o mesmo deve ocorrer numa linguagem de parâmetros, como na 


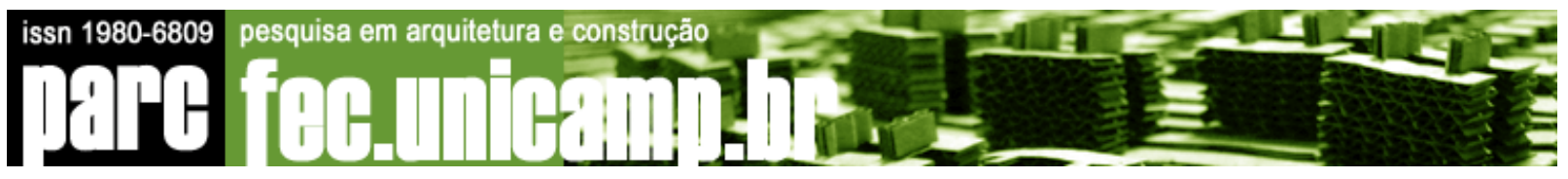

FIG.2-A. A combinação entre parâmetros em um nível gera novo parâmetro em nível superior, mostrando dependência deste em relação àqueles, como na FIG.2-B. As conexões são inviabilizadas quando da excessiva distância entre parâmetros, conforme ilustrado na FIG.2-C:

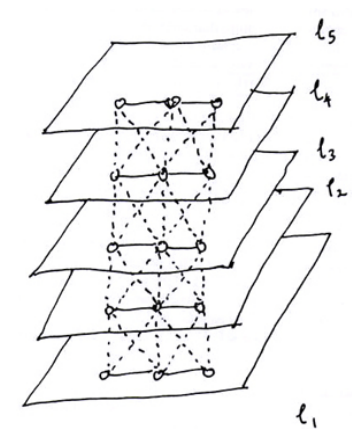

$\ell_{1}$

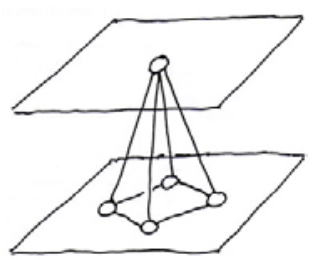

A: Conexões hierárquicas entre níveis $\quad$ B: Combinação entre parâmetros $\quad$ C: Distância excessiva entre nívei
FIGURA 2: Relação entre parâmetros de uma linguagem. Fonte: SALINGAROS, 2000, p.156.

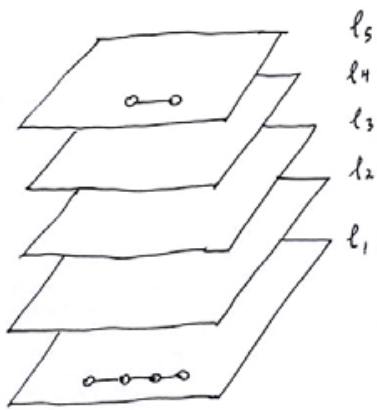

A: Conexões hierárquicas entre níveis B: Combinação entre parâmetros $\quad$ C: Distância excessiva entre níveis
FIGURA 2: Relação entre parâmetros de uma linguagem. Fonte: SALINGAROS, 2000, p.156.

O arranjo dos conceitos humanizadores em estrutura conceitual também visa facilitar uma avaliação critica ao longo do processo projetivo. Neste aspecto, as contribuições de J. Christopher Jones são valiosas. Jones (1969) argumenta que o controle na atividade projetual revela o valor prático da teoria de projeto, visto que supre as deficiências das outras duas abordagens em extremos opostos, a saber, a da criatividade tendo o projetista como mágico e a da racionalidade tendo o projetista como computador (processador de dados). Sem o referido controle, a geração de alternativas não-familiares em universo muito abrangente para ser explorado pelo pensar consciente não permite a comparação de resultados parciais de cada ação projetual aos requisitos do projeto como um todo.

Para a estruturação conceitual da proposta de estratégia da presente pesquisa foi observada a relação entre geometria espacial e aspectos comportamentais inerente aos parâmetros projetuais, utilizando-se em especial das investigações de Norberg-Schulz (1965) quanto à percepção espacial, por sua vez fundamentadas em Piaget, para quem as esquematizações primárias de natureza topológica que se transformam nos modos geométricos de organização baseiam-se na experiência concreta.

Visualizaram-se nos parâmetros projetuais as seguintes propriedades espaciais predominantes: Conformação, Progressão e Hierarquia, Limites e Permeabilidade, Contraste e Distinção. As propriedades "Conformação" e "Progressão e hierarquia" correspondem às esquematizações primárias da percepção espacial, respectivamente cercamento e continuidade, cujos graus variados caracterizam a relação interior-exterior, conforme 


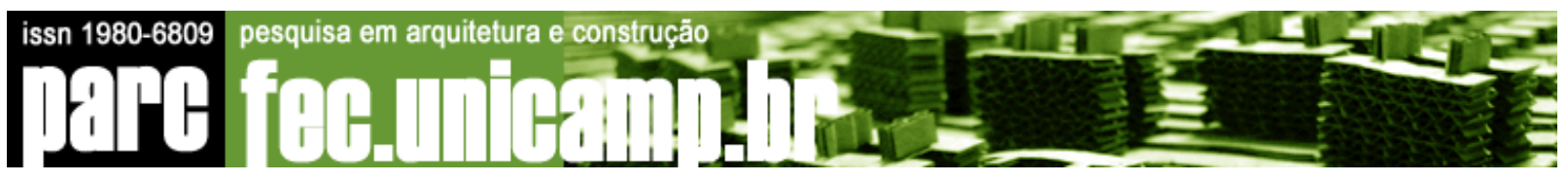

descritas por Norberg-Schulz (1965; 1976). "Conformação" traduz-se por lugar como aglomeração, reunião, ponto focal e permanência. A propriedade "Progressão e hierarquia" traduz-se por sucessão ininterrupta, movimento e familiaridade ao longo do percurso, equivalendo também a ritmo ou recorrência padronizada de elementos, um dos princípios de ordem apontado por Ching (1979) como recurso de organização formal e espacial. NorbergSchulz (1976) também enfatiza o aspecto do caráter na estrutura do lugar. O caráter seria determinado pela constituição material e formal do lugar e função do tempo e seus atributos se assemelham ao conteúdo dos parâmetros agrupados nas duas propriedades seguintes. A propriedade "Limites e Permeabilidade" traduz-se por bordas, contornos, costuras, barreiras e aberturas, e diz respeito ao caráter das fronteiras que definem o lugar: grau de permeabilidade, interface física com o entorno no nível do solo e pavimentos superiores, relação com edificações vizinhas e espaços externos à edificação. Por fim, a propriedade "Contraste e Distinção" traduz-se por variabilidade, diversidade, irregularidade ou aspereza, tendo forte impacto no caráter e identidade do lugar. Inclui os parâmetros que estimulam a diversidade de usos e de usuários bem como a exploração de estímulos sensoriais proporcionados por contraste de vistas, efeitos da luz natural e artificial, cores e qualidades táteis dos materiais.

A estratégia proposta engloba conjuntos de parâmetros distintos, a saber: os originais em Alexander et al. (1977) identificados nos projetos da amostra; os novos também identificados naqueles projetos; os originais incorporados aos novos parâmetros e, por fim, outros parâmetros originais que, apesar de não terem sido identificados nos projetos, foram acrescentados à estratégia por sua pertinência aos conceitos propostos. A FIG.3 abaixo ilustra os respectivos conjuntos de parâmetros considerados:

I (identificados);

N (novos identificados);

Inc (incorporados);

A (acrescentados).

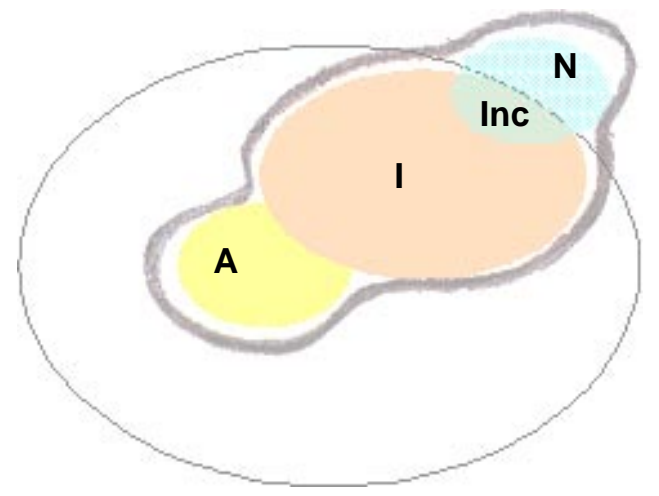

FIGURA 3: Conjuntos de parâmetros utilizados na estratégia projetual. 


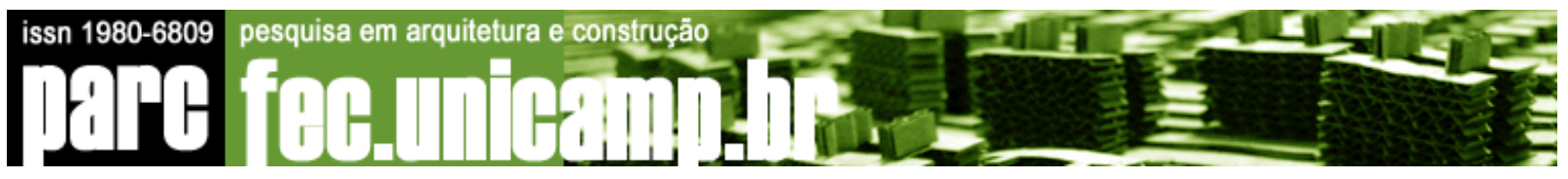

Os conceitos humanizadores combinam parâmetros projetuais e possuem caráter abrangente. Estruturados em estratégia de apoio ao processo projetual, constituem os elementos que podem contribuir para o atendimento das necessidades humanas enfocadas. A estratégia visa estimular o uso efetivo e criativo daqueles conceitos e consiste de enquadramento que relaciona os conceitos às propriedades espaciais predominantes e inerentes aos parâmetros, e é apresentada na escala do Senso de Urbanidade em três subcategorias de conceitos e em seguida ilustrada na TAB.2.

\section{i) SENSIBILIDADE AO AMBIENTE CONSTRUÍDO E NATURAL EXISTENTE}

Conjuntos organizados espacialmente de maneiras diversas, desde que conformando espaços externos positivos (de forma distinta e de igual importância à forma das edificações ao redor), esforçam-se por atender a especificidades e elementos naturais e construídos do terreno e entorno. Busca-se melhorá-los a partir de projeto que preserva e acentua as qualidades existentes tais como vista, vegetação, insolação e topografia, procurando contribuir para a melhoria do caráter da vizinhança, características irregulares do solo, formato do terreno ou topografia, e também através da criação de interfaces permeáveis entre terreno e entorno, entrelaçando caminhos, lugares e ambientes de transição ao longo dos limites. O desenho urbano excessivamente abstrato não facilita o entrelaçamento das edificações ao lugar, podendo resultar em configurações segregadoras que não permitem rede de espaços externos positivos permeáveis.

\section{ii) CONECTIVIDADE, LEGIBILIDADE E SUSTENTABILIDADE SOCIAL}

O desenho urbano que estrutura e estabelece hierarquia entre espaços externos positivos do conjunto e também entre estes e o sistema maior de espaços coletivos do tecido urbano garante uma melhor distribuição da acessibilidade. A conexão dentro-fora e a legibilidade são proporcionadas por meio de fronteiras permeáveis das arcadas, galerias, terraços e escadas abertas de acesso, aliadas a estruturas formais que geram um alto grau de conformação dos espaços resultantes de edificações com recuos laterais e frontais reduzidos ou nulos. Formatos diferenciados de percursos podem incentivar permanência ou contemplação e configurar pátios internos e conjunto de entradas similares. Fronteiras permeáveis podem estabelecer relação mais direta com a rua. A vivacidade urbana é incentivada por diversidade de usos na vizinhança e oferta de tipologias, dimensões e programas de moradia variados, contribuindo para a sustentabilidade social. A diversidade de 


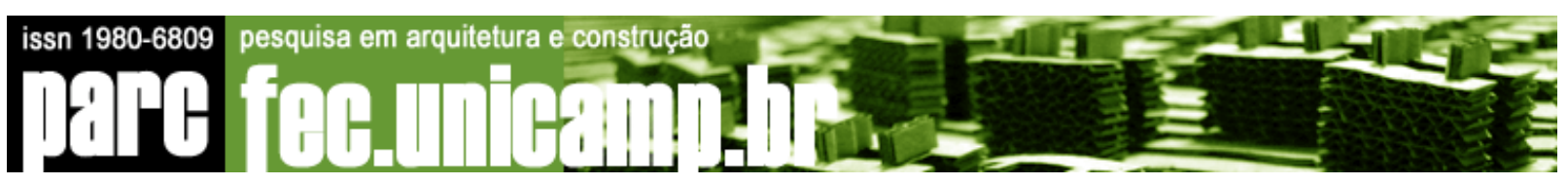

usuários ajuda a sustentar atividades de lazer, comerciais e de serviços e inclui a diversidade social.

iii) IDENTIDADE

A identidade para conjuntos e UHs individuais que abrangem diversidade de usuários podem se expressar, entre outros, por gradiente de privacidade no layout do conjunto. A demarcação de conjunto de entradas e transições no espaço físico da entrada das UHs contribuem para sua identidade. A vegetação também pode conformar e distinguir espaços. Variações modestas no relevo das superfícies, bem como no layout da cobertura, expressam partes identificáveis como coleção de edifícios menores conectados. Eventuais contrastes maiores no perfil geral da edificação podem enfatizar partes principais ou distintas, a entrada do conjunto e de espaços coletivos. 

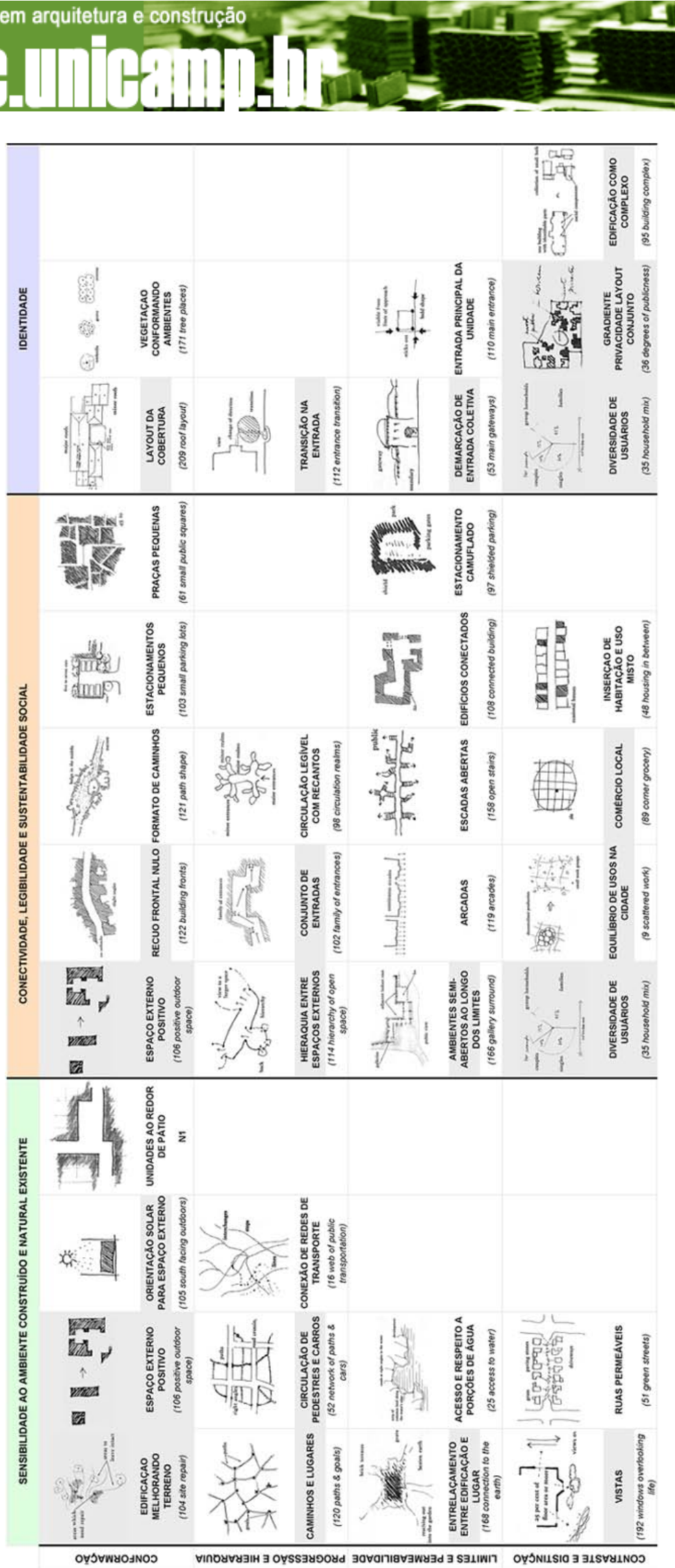

TABELA 2: Estratégia para o Senso de Urbanidade. Número e nome dos patterns originais em itálico. Fonte dos croquis originais: Alexander et al., 1977.

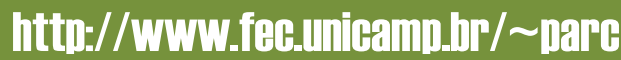




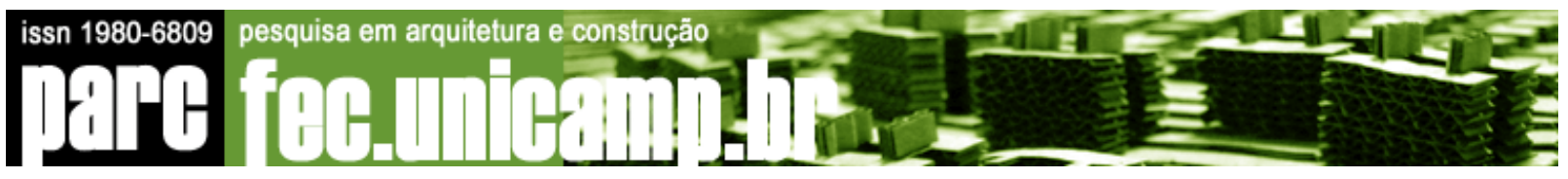

A proposta de estratégia para a escala do Senso de Habitabilidade é apresentada em três subcategorias de conceitos e em seguida ilustrada na TAB.3.

\section{i) HARMONIA ESPACIAL, CONFORTO AMBIENTAL E PRIVACIDADE}

Considerando as diversas possibilidades de agregação entre UHs, a escolha da melhor orientação solar para a implantação da edificação e espaço circundante e também do formato adequado de UHs agregadas para o melhor aproveitamento da luz e ventilação naturais têm implicação no gradiente de intimidade das UHs. As técnicas passivas para a sustentabilidade ambiental apresentadas a seguir podem também evitar a necessidade de outros recursos tecnológicos que implicariam em custos muitas vezes elevados, ou mesmo trabalhar de forma complementar a estes de modo a viabilizar seu uso de maneira eficiente. A opção por alas de forma alongada e estreita, horizontal ou verticalmente, facilita a obtenção de mais de uma orientação para as UHs e também o gradiente de intimidade. Porém, a agregação de UHs sobrepostas no sentido longitudinal com este formato alongado acarreta deficiência luminosa, que pode ser resolvida com recursos como, por exemplo, afastamentos parciais entre UHs, ou optando-se pela agregação das paredes laterais menores e não maiores (sentido transversal e não longitudinal). A obtenção de mais de uma orientação para UHs agregadas, especialmente em conjuntos de organização espacial adensada, acarreta a necessidade de outras estratégias conjuntas para o alcance da privacidade (especialmente visual) entre UHs confrontantes ou entre UHs e a rua. Por exemplo, a observação da distância entre UHs que se abrem uma para a outra, a criação de mini-pátios reservados para parte das aberturas, o uso de clarabóias, janelas altas, vidro corrugado ou translúcido, elementos opacos posicionados em ângulo em relação à abertura, elementos vazados (cobogós), venezianas sanfonadas ou brises articulados controláveis pelos usuários, vegetação, desnível de piso entre passeio e entrada e outros.

\section{ii) SENTIDO DE LAR}

Criar UHs que ofereçam adequação ao uso, lembrando que as atividades devem guiar a estrutura física e não o contrário, e gradiente de intimidade através de diferenciação física que possibilite interação social bem como senso de proteção. Expressões de centralidade e verticalidade representam extensões da identidade e orientação corporal humana no ambiente e se traduzem por áreas de encontro centrais, visíveis e ladeadas por fluxos de passagem, incluindo a eventual escada que distribui as atividades verticalmente para fora do

\section{http://WwW.for.uniBamphor/ part}




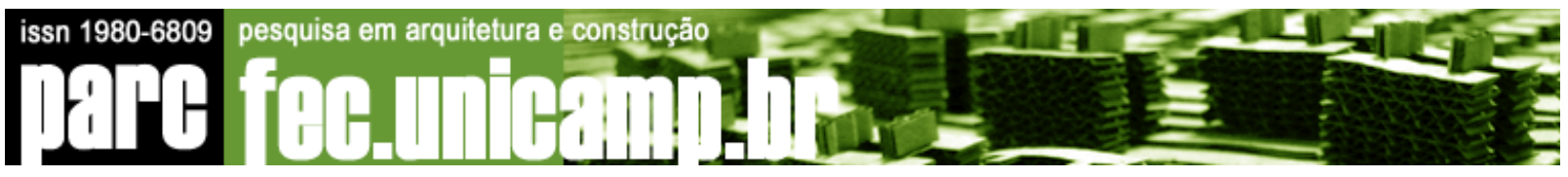

centro, acarretando uma boa distribuição e agenciamento entre ambientes. Os limites da habitação devem ser permeáveis criando zonas de transição através de diferenciações no percurso e criação de ambientes de entrada, terraços semi-elevados, varandas, saliências que conformam ambientes de contemplação, e outros recursos que visem tanto a comunicação como a privacidade, incluindo as estratégias já descritas. As aberturas, sua localização, dimensão e tipo, além de interferirem na adequação luminosa às diferentes atividades internas, interferem também na possibilidade de controle do gradiente de luminosidade e privacidade pelos usuários e na exploração do contraste luminoso e de vistas para o exterior, que podem contribuir para a orientação e agradabilidade do percurso entre ambientes.

\section{iii) OPÇÕES E FLEXIBILIDADE}

A flexibilidade de uso no layout interno das UHs, requerida por concursos de Habitação de Interesse Social (HIS) atuais que priorizam a adaptabilidade das UHs do conjunto a diferentes usuários ao longo do tempo, parece requisitar maior desenvolvimento em pesquisas de projeto, apesar de já ter sido idealizada pela arquitetura moderna. A planta livre que objetiva a fusão dos espaços pode levar ao caos ou à incongruência aos espaços de convívio, perda do gradiente de intimidade incluindo perda de privacidade visual e ou acústica. Para que a UH possa crescer ou ser alterada sem perda de coerência faz-se necessária definição clara de meio organizacional que reconheça partes primárias e secundárias, pressupondo que certas propriedades espaciais e qualidades requeridas que caracterizam a forma em questão permaneçam constantes. Sistemas construtivos e materiais adequados precisam ser enfocados nas diferentes situações da autoconstrução e da construção por empreiteira. Diversos parâmetros projetuais em Alexander et al. (1977) incentivam a multifuncionalidade ou flexibilidade espacial desde que se garanta a congruência entre estrutura física e espaço social. Ao contrário de alguns parâmetros, porém,

o conceito aqui proposto não sugere necessariamente a autoconstrução gradual e uso de materiais não industrializados: acredita-se que se a racionalidade construtiva for usada como meio e não como fim, pode ajudar na flexibilidade dos espaços e deve ser incorporada no processo de projeto de habitação coletiva. Quanto à possibilidade de expansão, determinadas organizações espaciais de conjunto são mais apropriadas a projetos que forneçam apenas o embrião da UH. Em geral, nos projetos de HIS a exigüidade de área das UHs individuais que precisam atender a famílias muitas vezes numerosas é a principal causa 


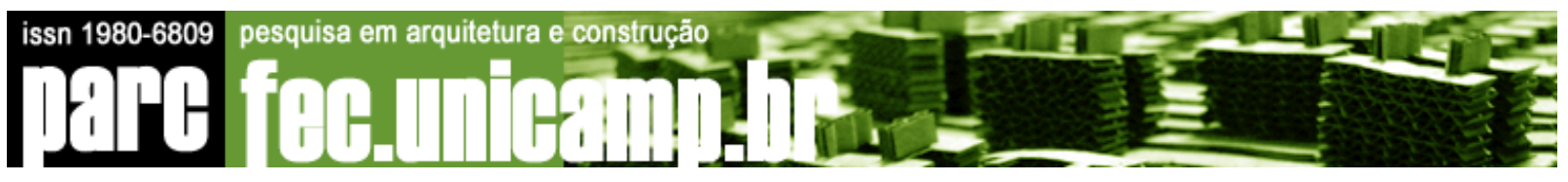

para a necessidade de expansão das UHs. Por outro lado, projetos que já ofereçam variedade de programas de moradia, algumas já com maior generosidade de área por UH visando uma abrangência maior de usuários em diferentes fases da vida, podem diminuir a necessidade de modificações e ampliações futuras. Em qualquer caso, a orientação especializada e acompanhamento quando da necessidade de expansão ou modificação do projeto será sempre necessária, visando à garantia de sua qualidade. 

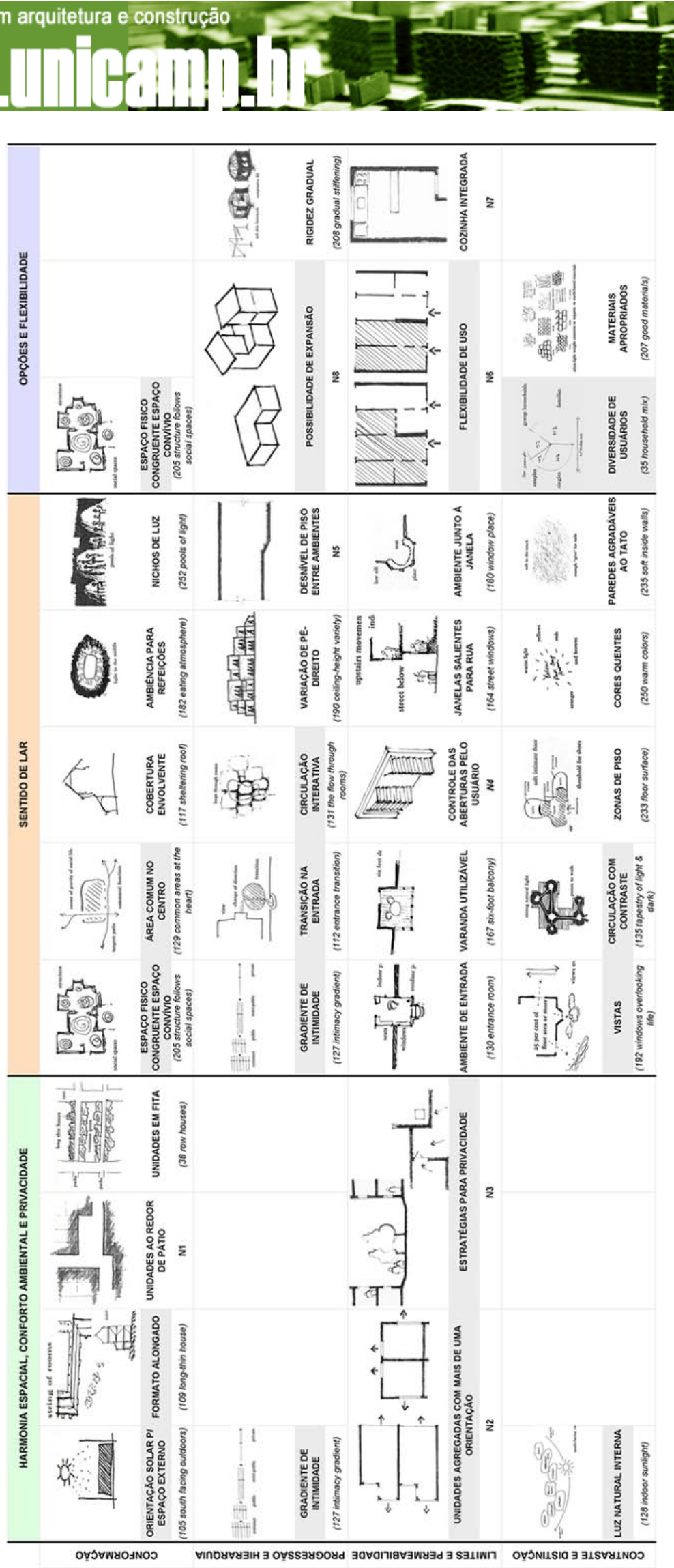

TABELA 3: Estratégia para o Senso de Habitabilidade. Número e nome dos patterns originais em itálico. Fonte dos croquis originais: Alexander et al., 1977.

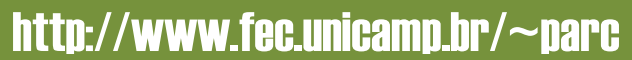




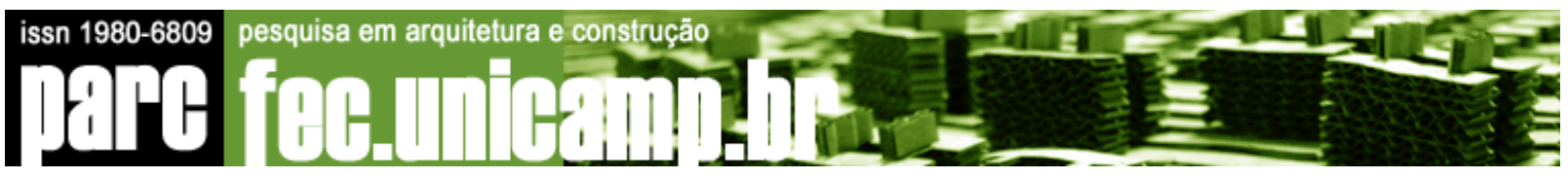

\section{Considerações finais}

O presente trabalho partiu do reconhecimento da importância da relação entre conceitos humanizadores e a qualidade espacial do projeto da habitação coletiva com vistas à integração entre o conhecimento qualitativo constatado em Alexander et al. (1977) e sua sistematização criativa na solução de problemas do projeto.

Para tanto, revisou-se literatura sobre pesquisas em metodologia de projeto a fim de amparar o aproveitamento daquele conhecimento no processo projetivo. A sistematização na solução de problemas do projeto sem prejuízo à criatividade insere-se em campo consolidado de pesquisa. Cross (2007) aponta os avanços e abrangência das pesquisas em metodologia de projeto nos últimos quarenta anos. A natureza complexa dos problemas de projeto sugere a necessidade de contribuições para a fase da concepção projetual, já que muitas soluções distintas são possíveis e muito tempo e esforço são gastos na definição e redefinição dos problemas. Teóricos como Norberg-Schulz (1965), Jones (1969), Rowe (1995) e Lawson (1997) reiteram a necessidade de equilíbrio entre os pensamentos divergente e convergente durante o projetar, que apresenta etapas similares ao processo criativo em outras áreas. Kowaltowski et al. (2006) oferecem reflexão sobre diferentes metodologias de projeto arquitetônico e acreditam que a qualidade do sistema de suporte ao projetista durante o estudo do objeto e de suas condições de uso reflete-se diretamente no processo e, esperase, na qualidade do produto. A estratégia de apoio aqui proposta buscou enfatizar a importância da relação entre os parâmetros bem como a clareza narrativa e de representação dos valores identificados e incorporados nos conceitos humanizadores, a fim de estimular seu uso efetivo e criativo no processo de projeto.

Buscou-se também embasar o conteúdo dos parâmetros projetuais selecionados em Alexander et al. (1977) como fatores de projeto para o melhor atendimento de necessidades sociais e psicológicas na habitação. A averiguação do atendimento àquelas necessidades na amostra de projetos em Barros (2008) sob o enfoque dos parâmetros constatou a relevância destes para a análise dos projetos. $\mathrm{O}$ arranjo concêntrico dos parâmetros em conjuntos temáticos (ver FIG.1) auxiliou na visualização de associações identificadas entre parâmetros de diferentes categorias, por sua vez fomentando a construção de conceitos de caráter propositivo e abrangente que incorporam parâmetros originais e novos.

Esta pesquisa sugere que os conceitos humanizadores construídos e enquadrados em estrutura conceitual podem vir a beneficiar o processo projetivo e a qualidade de projetos de habitação coletiva para qualquer faixa de renda. Os conceitos representam qualidades 


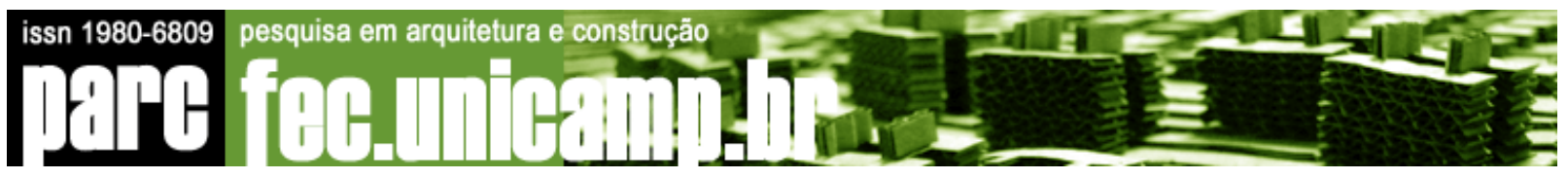

espaciais do ambiente construído que podem resgatar um senso de lugar e de habitar desde a escala da implantação à escala da UH. Espera-se que a estratégia possa constituir base flexível para a emergência de idéias e contribua para a reflexão e prática do processo projetivo visando à melhoria da qualidade da habitação coletiva com relação ao melhor atendimento de necessidades sociais e psicológicas de futuros usuários.

\section{Referências}

ALEXANDER, C. The timeless way of building. New York: Oxford Univ., 1979.

ALEXANDER, C.; ISHIKAWA, S.; SILVERSTEIN, M. A Pattern Language. New York: Oxford Univ., 1977.

BARROS, R. Habitação coletiva: a inclusão de conceitos humanizadores no processo de projeto. Campinas, 2008. Tese (Doutorado) - Faculdade de Engenharia Civil, Arquitetura e Urbanismo, Universidade Estadual de Campinas. Defendida em 13/10/2008.

BROADBENT, G.; WARD, A. (eds). Design methods in architecture. New York: G. Wittenborn, 1969.

CHING, F. Architecture: form, space and order. New York: Van Nostrand Reinhold, 1979.

CROSS, N. Forty years of design research. Design Studies, v. 28, n. 1, p.1-4, Jan. 2007.

JONES, C. The state-of-the-art in design methods. In: BROADBENT, G.; WARD, A. (eds).

Design Methods in Architecture. New York: G. Wittenborn, 1969., p. 193-197.

JUTLA, R. Christopher Alexander's design theory from Notes on the synthesis of form to $A$ pattern language. Design Methods, v. 27, n. 4, p. 1899-1913, Oct-Dec 1993.

KOWALTOWSKI, D.; CELANI, M.; MOREIRA, D.; PINA, S.; RUSCHEL, R.; SILVA, V.; LABAKI, L.; PETRECHE, J. Reflexão sobre metodologias de projeto arquitetônico, Ambiente Construído, v. 6, n. 2, p. 7-19, 2006.

LASEAU, P. Graphic thinking for architects and designers. New York: Van Nostrand Reinhold, 1989.

LAWSON, B. How designers think. 3rd ed. Oxford: Architectural, 1997.

NORBERG-SCHULZ, C. Intentions in architecture. Cambridge: M.I.T., 1965.

. The phenomenon of place, Architectural Association Quarterly, v. 8, n. 4, p.

3-10, 1976.

ROWE, P.G. Design Thinking. 6th ed. Cambridge: M.I.T., 1995.

SALINGAROS, N. The structure of pattern languages. Architectural Research Quarterly, v. 4, n. 2, p.149-161, 2000. 